\title{
Smooth muscle pseudotumours: a potentially confusing artefact of rectal biopsy
}

\author{
E K DANKWA, J D DAVIES \\ From the University Department of Pathology, Bristol Royal Infirmary, Bristol
}

SUMMARY An artefactual smooth muscle lesion was found in seven of 500 consecutive rectal biopsy specimens. The lesions had the deceptive appearance of a genuine tumour although none of the patients with the lesion had presented with a rectal mucosal swelling. The morphology of the lesion and its poor reproducibility under experimental conditions suggested that it was an artefact of the biopsy procedure: it was easily reproduced in resected specimens of large bowel using punch or basket forceps but not when using flat forceps.

The presence of the lesion seems to depend on the type of forceps used rather than on differences in deployment and seems to be caused by avulsion of the superficial part of the muscularis propria and its incorporation into the tissues included in rectal biopsy specimens.

Smooth muscle tumours of the large bowel are rare. ${ }^{12}$ Most occur in the muscularis propria and few are associated with the muscularis mucosae. Before formulating a diagnosis of potentially aggressive neoplasia, however, it is necessary to exclude the various forms of pseudotumour. The sporadic but fairly common occurrence of a tumour-like lesion in routine rectal biopsy specimens led to this investigation.

In general, rectal biopsy is a safe procedure with little damage to tissue deep in the wall of the rectum. We report on a peculiar lesion found adjacent to the muscularis mucosae which simulates a smooth muscle tumour in rectal biopsy specimens. The nature and origin of the lesions was investigated by clinical enquiry, morphological study, and by attempted experimental reproduction.

\section{Material and methods}

All rectal biopsy specimens received in the 18 months between January 1984 and June 1985 at this hospital were reviewed. Most of the specimens had been taken to evaluate the possible presence or activity of inflammatory bowel disease. The age distribution of the 512 cases is shown in table 1: the mean age was 42 years (range 30 to 69). There were 211 men and 301 women in this series. Of the 512 biopsy specimens, 299 were assessed as showing clinically important inflammation of various types, and 180 were reported to be normal. There were also 12 carcinomas, five adenomas, and

Accepted for publication 18 February 1988 two showed metaplastic polyps. Other pathology included melanosis coli $(n=5)$, irradiation effects $(n=4)$, solitary ulcer or mucosal prolapse $(n=3)$, and one case each of amyloidosis and haemorrhoids.

In the course of the retrospective review seven cases showing the muscular lesion which is the subject of this paper were identified. The clinical notes of these cases were consulted with particular reference to the presence or absence of macroscopically protruding lesions seen at proctoscopy.

The shape of the specimens in the histological sections was also assessed at dissection microscopy into those with a curved mucosa, and those with a relatively flat mucosa. No attempt had been made before or after fixation to flatten out the rectal biopsy specimens in this series.

Subsequently an attempt was made to reproduce

Table 1 Age distribution of patients submitted to rectal biopsy and those with the pseudotumours

\begin{tabular}{lcl}
\hline Age (years) & Rectal biopsy patients & $\begin{array}{l}\text { Patients with } \\
\text { pseudotumours }\end{array}$ \\
\hline $0-10$ & 0 & 0 \\
$11-20$ & 29 & 0 \\
$21-30$ & 120 & 3 \\
$31-40$ & 94 & 1 \\
$41-50$ & 48 & 0 \\
$51-60$ & 62 & 1 \\
$61-70$ & 85 & 2 \\
$71-80$ & 56 & 0 \\
$81-90$ & 18 & 0 \\
Total & 512 & 7 \\
\hline
\end{tabular}




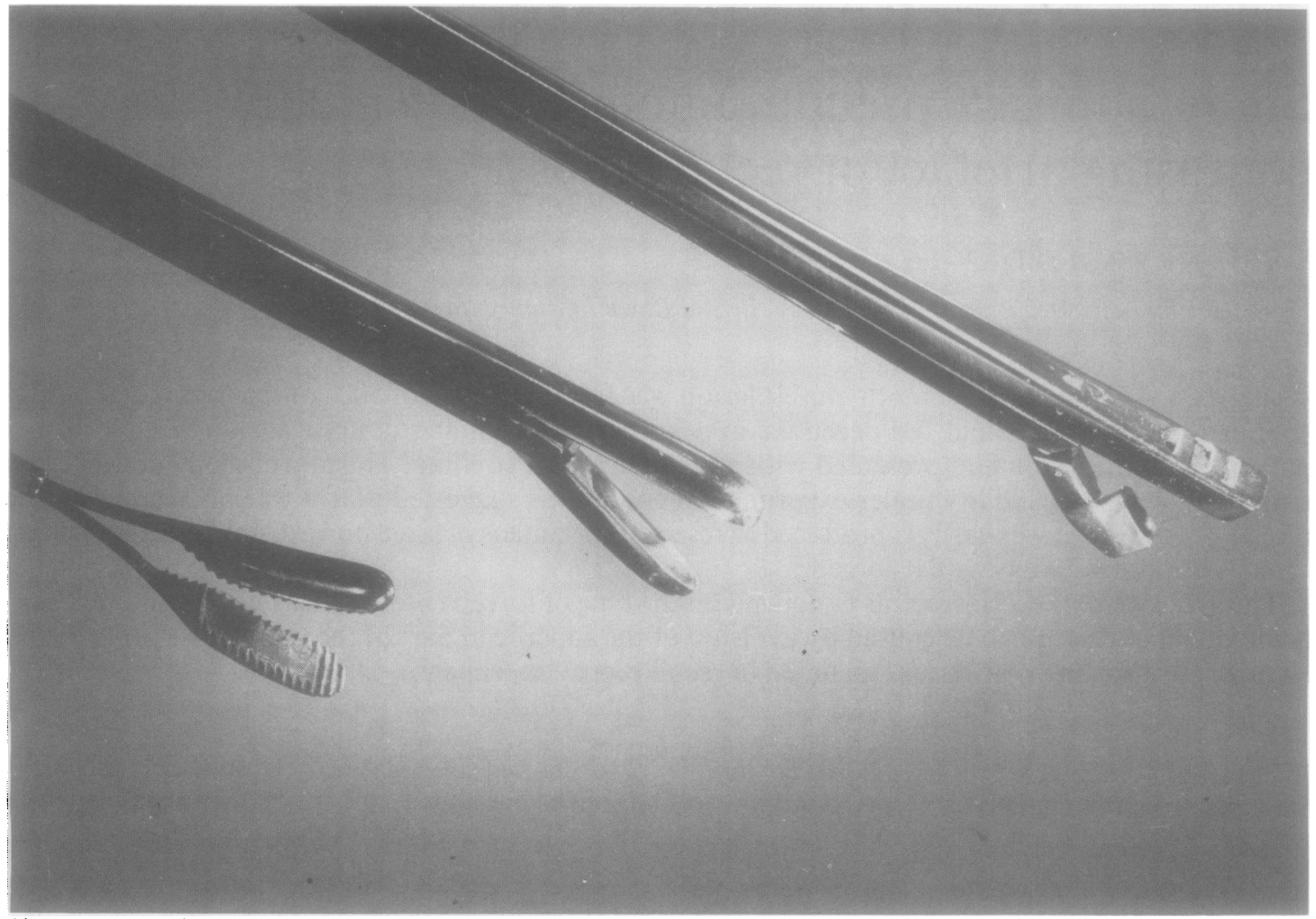

Fig 1 Snares of three types of rectal biopsy forceps; from left to right, flat, basket, and punch.

experimentally the muscular lesions. For this purpose, freshly resected large bowel specimens from patients with colorectal carcinoma were used. The experimental specimens were taken from macroscopically normal mucosa at a distance of at least $5 \mathrm{~cm}$ from the margin of the carcinoma, avoiding any gross abnormality. Three types of forceps were used (fig 1)namely, punch (Chevalier Jackson, Seward), basket (Paterson forceps, Downs Brothers) and flat (Lockhart-Mummery, Downs Brothers) rectal biopsy forceps. Two standard clinical techniques of rectal biopsy (R A Mountford, personal communication) were also used to obtain the experimental biopsy specimens from the resected sections; these were the "plucking" and the "twisting" techniques.

A pilot study was undertaken to assess the possible influence of fixation on the resected specimens, and specimens were immersed in physiological saline and $10 \%$ or $40 \%$ formol saline. All the experimental "biopsies" so obtained were processed routinely on a VIP machine (Miles Scientific) in the same manner used for the routine clinical biopsy specimens examined in the survey described above, embedded in paraffin wax (melting point $56^{\circ} \mathrm{C}$ ), sectioned at $5 \mu \mathrm{m}$ depth on a rotary microtome, and stained by haematoxylin and eosin.

Statistical analyses were performed on the data using standard $\chi^{2}$ analysis ${ }^{3}$ with appropriate Yates's correction for small expected numbers in the $2 \times 2$ contingency tables. ${ }^{3}$ The probability distribution tables used were those published by Diem and Lentner. ${ }^{4}$

\section{Results}

Of the 512 rectal biopsy specimens, seven $(1.4 \%)$ showed a well circumscribed oval or circular tumourlike mass of smooth muscle. This was invariably closely related to the muscularis mucosae, although there was usually a clear plane of separation from the muscularis mucosae itself. In most cases the muscular mass was present in the superficial submucosa (fig 2), but in one instance it was found in the lamina propria of the mucosa (fig 3). The component smooth muscle cells were uniform and displayed no mitotic activity or nuclear pleomorphism. They were arranged in a circumferential manner, which generally reflected the spherical contour of the mass. The lesions were all centrally situated in the biopsy specimens and measured 1.0 to $2.0 \mathrm{~mm}$ in maximum diameter.

There was a bimodal age distribution of the patients with the lesion, which closely resembled the parent population of the patients submitted to rectal biopsy (table 1). The male : female sex ratio of patients with the smooth muscle lesion was $2: 5$, which was not significantly different from that of the whole series of 


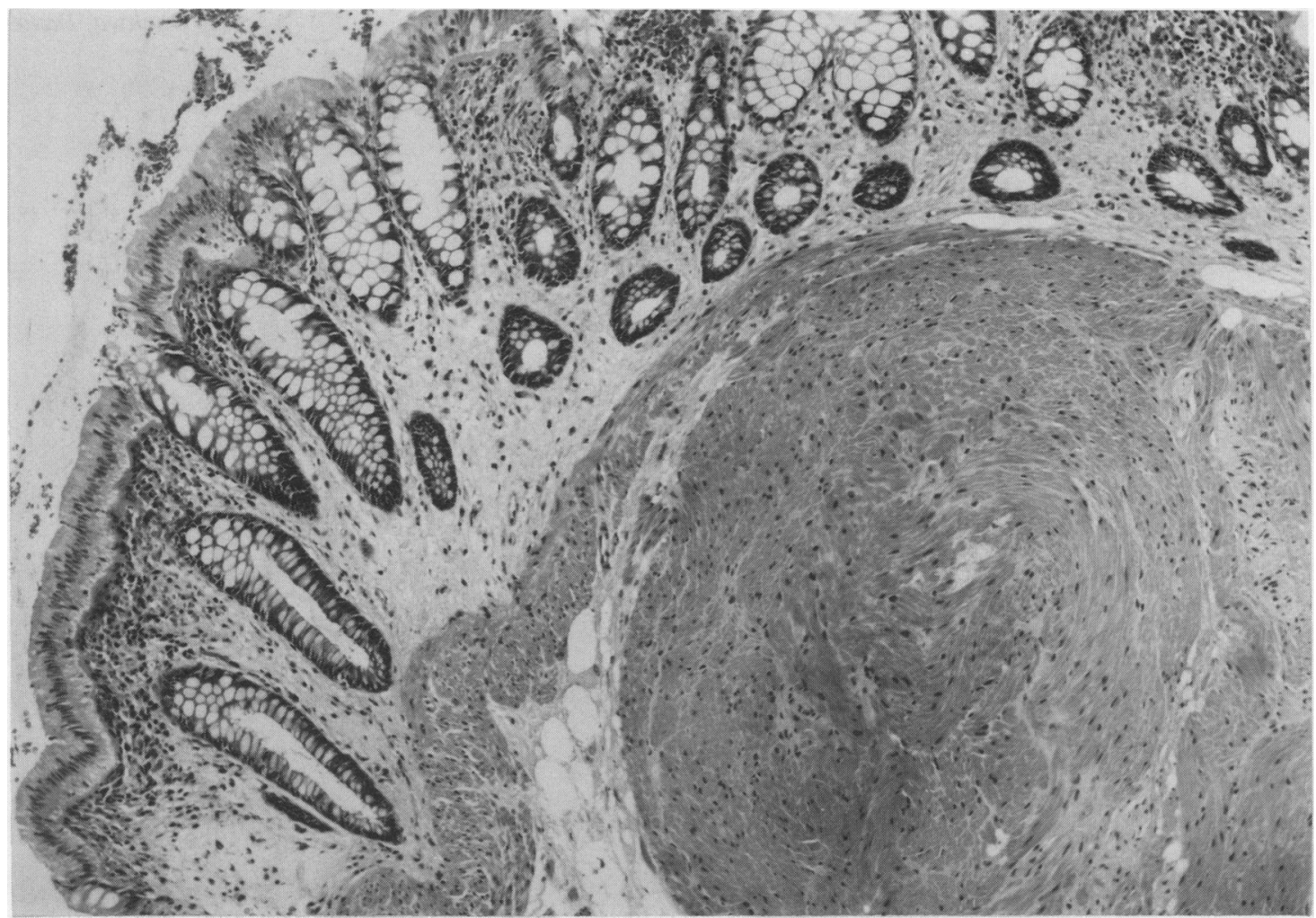

Fig 2 Pseudotumourous ball of smooth muscle (lower right) in submucosa showing close apposition to overlying muscularis mucosae and whorled arrangement of uniform component cells. (Haematoxylin and eosin)

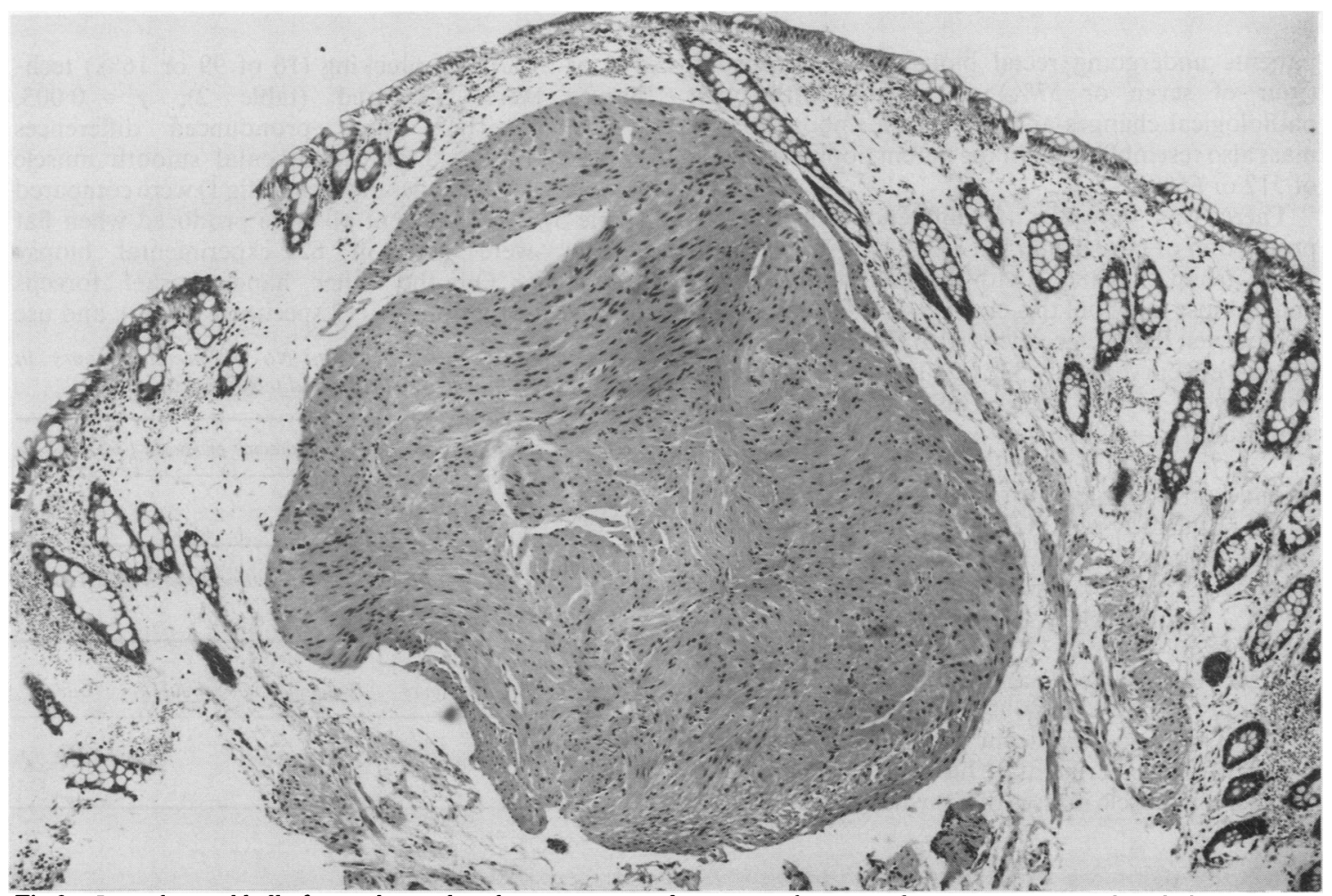

Fig 3 Irregular oval ball of smooth muscle in lamina propria of mucosa without any obvious continuity with underlying fragmented muscularis mucosae. (Haematoxylin and eosin) 


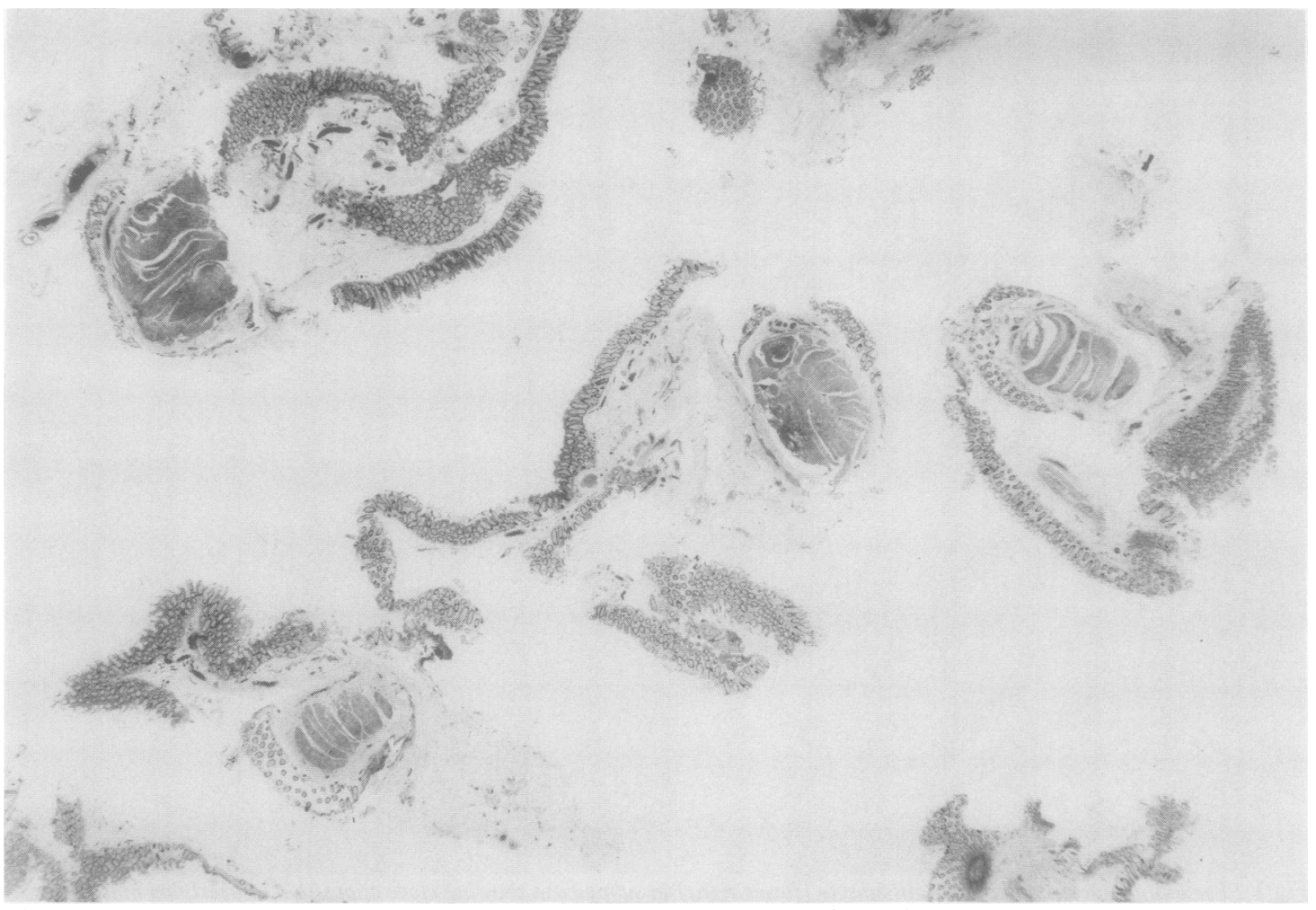

Fig 4 Four experimental biopsy specimens containing pseudotumourous balls of smooth muscle. (Haematoxylin and eosin)

patients undergoing rectal biopsy. The proportion (four of seven or $57 \%$ ) of patients with other pathological changes apart from the smooth muscle mass also resembled that of the parent population (332 of 512 or $65 \%$ ).

There was, however, a difference between the proportion of curved and flat rectal biopsy specimens in the group of patients with the smooth muscle ball and in those in whom this change was not present. Six of the seven $(86 \%)$ specimens with the smooth muscle lesion were curved; only 337 of $505(67 \%)$ lacking the lesion were of this type. This difference was not significant $\left(\chi_{c}^{2}=0.41\right)$.

\section{EXPERIMENTAL REPRODUCTION OF LESIONS}

In the pilot study no difference in the yield of smooth muscle lesions was found between the large bowel specimens immersed in physiological saline, or in $10 \%$ or $40 \%$ formol saline. For reasons of convenience therefore, all of the 213 "biopsy" specimens obtained and analysed (tables 2 and 3) were from colorectal resections immersed in $10 \%$ formol saline.

There was no significant difference between the proportion of experimental "biopsy" specimens yielding smooth muscle masses (fig 4) when the twist (24 of
114 or $21 \%$ ) and plucking ( 16 of 99 or $16 \%$ ) techniques were compared (table 2); $\chi_{\mathrm{c}}^{2}=0.003$, $\mathrm{p} \simeq 0.95{ }^{4}$ There were pronounced differences between the yield of experimental smooth muscle lesions when the types of forceps (fig 1) were compared (table 3). No lesions at all were produced when flat forceps were used in 62 experimental biopsy specimens. On the other hand, basket forceps produced 21 lesions in 112 specimens (19\%), and use

Table 2 Association between No of pseudotumours in experimental biopsy specimens and technique used

\begin{tabular}{llll}
\hline Technique & No of tumours & Pseudotumours produced & Total \\
\hline Twist & 90 & 24 & 114 \\
Plucking & 83 & 16 & 99 \\
\hline
\end{tabular}

Table 3 Experimental yield of pseudotumours and type of forceps used

\begin{tabular}{lllc}
$\begin{array}{l}\text { Type of } \\
\text { forceps }\end{array}$ & No of tumours & Pseudotumours produced & Total \\
\hline Flat & 62 & 0 & 62 \\
Basket & 91 & 21 & 112 \\
Punch & 20 & 19 & 39 \\
\hline
\end{tabular}


of punch forceps led to 19 lesions in 39 biopsy specimens $(49 \%)$. There was a highly significant difference between these three proportions $\chi_{[2]}^{2}=37.33, \mathrm{p}<0.0005$.

\section{Discussion}

The documented rarity of smooth muscle tumours in the large bowel ${ }^{15}$ contrasts with the prevalence of the pseudotumour described in this paper. The lesion was first recognised as a result of misdiagnosis by one of the authors 10 years ago. The patient in question had no recognisable tumour on proctoscopy and has remained in good health since. Thereafter many such lesions have been seen in routine practice. The estimate of an incidence of about $1 \%$ in the 500 surveyed cases accords with our wider experience.

Clinically there was no evidence that these lesions were even present at proctoscopy, let alone that they were neoplastic. No expression of tumour growth was found when the patients with the lesion were followed up. Furthermore, there was no difference in sex incidence compared with the parent population of patients submitted to rectal biopsy, nor of prevalence in a particular age group. The bimodal age distribution reflected that of the survey patients (table 1). Such features as these would be extremely unusual for a genuine smooth muscle tumour. The lack of predilection for either sex or a particular age group, although varying in different anatomical sites, is quite unlike most smooth muscle tumours, ${ }^{6-10}$ or even nonneoplastic proliferation of smooth muscle." The presence or absence of other clinically important pathological changes in the biopsy specimen evidentally bore no relation to the incidence of the lesions.

None the less the lesions are easily confused on superficial histological examination with a genuine tumour or hamartoma of the smooth muscle of the rectum. The detailed morphology of the smooth muscle balls, however, differs from an indigenous lesion. The lesions were always centrally situated in the biopsy specimens. They were also of relatively uniform size. Although always closely located near the muscularis mucosae, there is some variation in the tissue siting of the lesions. Most are present in the submucosa but a few occur in the mucosa. There is usually no proper continuity between the muscle balls and the muscularis mucosae itself (fig 2). Unlike smooth muscle tumours, none of our cases showed mitotic activity or cellular pleomorphism. Nevertheless, we are aware of at least one case in which these features were present, and which led to a needlessly ominous interpretation. Probably the main protection against misdiagnosis is an awareness of the likely nature of most possible smooth muscle tumours in a rectal biopsy specimen.

The experimental reproduction of the lesions was achieved by the use of basket or punch biopsy forceps. Although the circumstances of the "biopsy" procedure were artificial, and a deliberate attempt was made to achieve a traumatically deep biopsy the lesions were successfully produced in $20-50 \%$ of cases when basket or punch forceps were used (fig 1). Clearly, a more gentle technique in clinical practice results in a much lower incidence of the lesions. The muscle in the lesions seems to come from the superficial aspect of the muscularis propria. It is then impacted into the more superficial layers of tissue included in the biopsy. It is not surprising, therefore, that most of the lesions are present in the submucosa, and that only a few are herniated as far as the lamina propria of the mucosa. The successful reproduction of the lesions from devitalised and formalin fixed tissue indicates that muscular contraction itself plays no part in the formation of the balls of muscle.

Our study suggests that the routine techniques of rectal biopsy with basket or punch forceps may lead to damage of tissue deeper than that usually included in a rectal biopsy specimen. Use of the flat biopsy forceps does not seem to carry the same hazard. Possibly the avulsion of muscle from the muscularis propria may be symptomatic of additional but unrecognised tissue damage in this common diagnostic procedure.

We are grateful to our gastrointestinal colleagues in the Bristol Royal Infirmary, in particular Dr R A Mountford for access to clinical information, and also for advice about the types of forceps in use, and for tuition in the current techniques of rectal biopsy. Our thanks are also due to Dr J L Channer for help in the early stages of this study, and to Mr C C Jeal for facilitating the photomicrographs.

\section{References}

1 Morson BC, Dawson IMP. Gastrointestinal pathology. 2nd ed. Oxford: Blackwell Scientific, 1979:686-7.

2 Walsh TH, Mann CV. Smooth muscle neoplasms of the rectum and anal canal. Br J Surg 1984;71:597-9.

3 Fisher RA. Statistical methods for research workers. 10th ed. Edinburgh: Oliver \& Boyd, 1948:78-113.

4 Diem K, Lentner C. Scientific tables. 7th ed. Basle: Ciba-Geigy, 1970:36-9.

5 Anderson PA, Dockerty MB, Bluie LA. Myomatous tumors of the rectum: leiomyomas and myosarcomas. Surgery 1950:28: 642-50.

6 Skandalakis JE, Gray SW. Smooth muscle tumors of the alimentary tract. Springfield, Illinois: C C Thomas, 1962:109.

7 Kusminsky RE, Bailey W. Leiomyomas of the rectum and anal canal: report of six cases and review of the literature. Dis Colon Rectum 1977:20:580-99.

8 Ranchod M, Kempson RL. Smooth muscle tumors of the gastrointestinal tract and retroperitoneum. Cancer 1977; 39:255-62.

9 Wile AG, Evans HR, Romsdahl MM. Leiomyosarcoma of soft tissue: a clinicopathologic study. Cancer 1981;45:1022-32.

10 Golden T, Stout AP. Smooth muscle tumors of the gastrointestinal tract and retroperitoneal tissues. Surg Gynecol Obstet 1941;73:784-810.

11 Channer JL, Davies JD. Smooth muscle proliferation in the hilum of superficial lymph nodes. Virchows Arch (Pathol Anat) 1985;406:261-70.

Requests for reprints to: Dr JD Davies, University Department of Pathology, Bristol Royal Infirmary, Bristol BS2 8HW, England. 